\title{
Export variety and the economic performance of countries
}

\author{
Pier Paolo Saviotti • Koen Frenken
}

Published online: 15 February 2008

(C) Springer-Verlag 2007

\begin{abstract}
We explore the relationship between export variety and economic development, using data on OECD countries between 1964 and 2003. We show that structural change in the world economy has a particular arrow of time leading to a growing variety of exports. Distinguishing between related variety (within sectors) and unrelated variety (variety between sectors), we also show that related variety stimulates growth instantaneously, while unrelated variety only promotes growth with a considerable time lag. This finding is in line with the evolutionary notions that economic development and international trade patterns are path dependent.
\end{abstract}

Keywords Related variety · Unrelated variety · Economic development · Trade · Path dependence

JEL Classification $\mathrm{B} 25 \cdot \mathrm{F} 10 \cdot \mathrm{O} 11 \cdot \mathrm{O} 19 \cdot \mathrm{O} 30 \cdot \mathrm{O} 49$

\section{Introduction}

It seems clear that, at least since the industrial revolution, technological change played an important role contributing to economic development. As a consequence, many new products, processes and services entered the composition of the economic

P. P. Saviotti $(\square)$

UMR GAEL, Université Pierre Mendés-France, P. O. Box BP 47, 38040 Grenoble, Cedex 9, France e-mail: saviotti@grenoble.inra.fr

P. P. Saviotti

GREDEG, CNRS, UNSA, 250 rue Albert Einstein, 06560 Valbonne, France

\section{K. Frenken}

Urban and Regional Research Centre Utrecht (URU), Section of Economic Geography, Faculty of Geosciences, Utrecht University, P. O. Box 80115, 3508 TC Utrecht, The Netherlands e-mail: k.frenken@geo.uu.nl 
system. The outcome of these changes in the composition of economic systems was to raise income per head and to allow a growing diversification of productive structures and of consumption. It is also evident that the changes in composition of the economic system and the growing wealth to which they contributed were not uniformly distributed. Countries that did not manage to enter the production of emerging goods and services remained behind both in technology and in income per head.

In the following, we take the view that these changes in composition were not only a consequence of previous economic development but also a determinant of its future potential. We show, using OECD data, that structural change in the world economy has a particular arrow of time leading to a growing variety of exports. We explore how countries at different levels of economic development can keep developing in the presence of a trend towards growing variety. We do this by measuring the impact of export variety on the growth in terms of GDP per capita and in terms of labor productivity. We distinguish between related variety (within sectors) and unrelated variety (variety between sectors), and show that related variety stimulates growth instantaneously, while unrelated variety promotes growth with a considerable time lag. We understand this difference as stemming from time scales at which incremental and radical structural adjustments take place.

\section{Economic development}

Since the industrial revolution, the emergence of new technologies and of organizational innovations made a very considerable contribution to the enormous rise in wealth that took place in the following period, thus giving rise to faster economic growth than at any time in the past. These innovations initially raised the efficiency of a number of functions that had always been carried out by human beings, such as the production of food and clothing and the speed of transport. However, as the development of the economy proceeded, powered by the growing efficiency of the new technologies, both the production and the consumption structures became increasingly diversified. New types of products and services were created and became increasingly differentiated. The overall development path that we can observe was jointly determined by the growth of efficiency and by the growth of creativity. Here, efficiency growth is represented by the fall of the ratio of inputs used to outputs produced at a constant output structure, whereas creativity is the activity which gives rise to novelty, essentially the result of innovation. As will be seen later, these two trends are by no means independent. The creation of greater wealth for many people has been obtained by means of profound changes in the production structure of countries, a development which has been accompanied by changing patterns of international trade.

While this pattern of development can be described by one or more trends, such as the growth of efficiency or of creativity, these trends were not followed by all the countries in the world economic system. In fact, probably the greatest economic divergence which has been created in human history has taken place since the industrial revolution. During this period, the inter-country distribution of income per head became increasingly skewed (Helpman 2004). Although economic development is a very complex phenomenon affected by many factors which are not yet 黑 Springer 
completely understood, a link can be clearly established between the structure of the economic system and its capacity to grow in the long run. The increasingly skewed international distribution of income per head since the industrial revolution can be closely related to the differential changes in the productive structure of nations, itself the result of a differential capacity to innovate. At any time since the industrial revolution, the most advanced technologies, production techniques and organizational forms were concentrated in the small number of countries that had the highest incomes per head.

There are, however, few long-term studies on the relation between the composition of national economies and their economic development. Most of the evidence about changes in the composition of the economic systems comes from studies of structural change. Salter (1960) found that the scope for productivity advance differs markedly across industries, mainly due to different rates of technological progress. Industries with high rates of productivity growth were expected to increase their share of output and employment. Structural change would thus be as important a contributor to overall growth as increases in productivity within individual industries. Cornwall (1977) considered that manufacturing was the economy-wide engine of economic growth. This would happen because the manufacturing sector displays dynamic scale economies through learning-by-doing. As production expands, the scope for learning and productivity becomes larger. Furthermore, due to its strong backward linkages to other sectors, manufacturing influences, and presumably increases, the rate of output growth and possibly the rates of productivity growth in other sectors. Cornwall's hypothesis was confirmed by empirical work for the years 1950s and 1960s.

More recent empirical work by Fagerberg (2000) and by Fagerberg and Verspagen (2002) confirmed the general importance of structural change but pointed to its changed role with respect to the periods studied by Salter and by Cornwall. For the period 1973-1990 Fagerberg found that the overwhelming part of total productivity growth was accounted for by productivity growth within individual industries. According to Fagerberg this does not necessarily imply that structural change has become unimportant, but that its role has changed. In particular, today's leading industries are those related to Information and Communication Technologies (ICT) as opposed to chemicals, electricity, motor cars etc. Advances in productivity growth in ICT could have spilled over to other sectors, thus raising their rates of productivity growth. As a consequence, rates of productivity growth might have been wrongly assigned to different sectors. Fagerberg and Verspagen (2002) tested Cornwall's hypothesis for the period after the 1970s. They found that manufacturing still played the role of engine of growth for newly industrializing countries but not for industrialized countries. They explained this change by a type of structural change which was both internal to manufacturing itself and that could also cross the boundaries between manufacturing and services. From these studies, we can draw the conclusions that a) structural change is an important component of economic development and that $b$ ) the use of highly aggregate and infrequently changed industrial classifications is not the ideal way to detect and to study the role of qualitative change in economic development.

Another strand of literature emphasizes the role of institutions in long-term economic development (North 1990; Landes 1998). Observed development patterns 
are more likely to have been the result of the co-evolution of technologies and institutions than of the simple invention or adoption of superior technologies (Nelson 1995). Countries that later became leaders could have started by establishing an initial advantage in either technologies or institutions, an advantage which led to an improvement in the other co-evolving variable and which in turn gave rise to a feed back positively affecting the initial source of advantage. ${ }^{1}$

The observed growing divergence in income per head and in productive structures during the course of economic development implies that the co-evolution discussed above only took place in some countries. In general, we can expect innovation to be created locally and to cause income levels to diverge among countries. On the other hand, phenomena such as imitation and diffusion tend to reduce income differences within the world economic system. The obvious conclusion is that very little imitation of the leading technologies has taken place since the industrial revolution. The countries which first introduced important innovations managed to become "Schumpeterian entrepreneurs" which could transform a temporary monopoly into a long range one. As a consequence, a productive structure emerged in which a limited number of countries controlled the most advanced productive techniques, and continue to diversify within these techniques, while other countries remained at a substantial distance from the technological frontier of the time.

Recent evidence about the persistent asymmetry of the international distribution of technological capabilities and the resulting specialization patterns comes from studies on the dynamics of export patterns (Haussman and Rodrik 2005; Hidalgo et al. 2007). These studies show how the creation of a capability in a certain sector substantially increases the probability of diversifying in related sectors. This dynamics implies that income differences across countries are expected to be persistent. It also shows the path- dependent nature of economic development at the national level, as future opportunities for growth through structural change are conditioned by the existing economic structure. As a consequence of these considerations, we can distinguish within economic development long term secular trends, which can in principle be expected to affect equally all countries, and persistent asymmetries, which preserve high degrees of country specificity in both output structure and in the institutional configurations underpinning such structure. ${ }^{2}$

\section{Variety, trade and economic growth}

The aspect of economic development we consider to be central is the creation of new activities giving rise to qualitative change, and thus leading to changes in the composition of the economic system. A more common way of describing the same situation is to say that the creation of new activities gives rise to structural change.

\footnotetext{
${ }^{1}$ Factor endowments are generally acknowledged to be important determinants of economic development through their effect on export specialization patterns. However, effects of endowments on the rate of development are expected to be minor, and to decrease in the future as economic development becomes increasingly knowledge-based.

2 The observation of such persistent asymmetries has also given rise to the concept of the national innovation system (Freeman 1987; Lundvall 1992; Edquist 1997).
} 
Structural change is usually measured as the change in the number and relative weights of the sectors constituting an economic system. In a sense, qualitative change is a broader phenomenon than structural change, since (1) it can be present at lower levels of aggregation than sectors and (2) it refers also to changes in the structure of institutions. Qualitative change takes place at several different levels (Saviotti 1996). First, new objects are produced; second, generally the activities required to produce the new objects are different from those used for the pre-existing objects, although a one-to-one correspondence between objects and activities does not exist; third, the institutional infrastructure required for the production and utilization of the new objects is often different from that required for the old objects. However, for the purposes of this paper, the differences will not be stressed. Both qualitative and structural changes affect the composition of the economic system, defined as the list of entities required to describe the economic system. In what follows, we stress that both qualitative and structural changes affect the composition of the economic system and thus contribute to economic development.

A variable that we can use to represent change in the composition of the economic system is its variety or diversity. In the present paper, these two terms are used as synonyms. Variety can be defined as the number of actors, activities and objects required to describe the economic system. There is considerable empirical evidence that the variety of the most developed economic systems has considerably increased since the time of the industrial revolution. The presence of many new objects, such as airplanes, computers, television, etc., of which no analogue was present in previous economic life, and the fact that, in general, these new objects did not substitute any pre-existing ones, leads to a strong suspicion that the variety of the economic system has grown. ${ }^{3}$

To the extent that the previous observation is accepted, we have to ask ourselves if the variety of the economic system is only a consequence of economic development. The previous considerations on the process of structural change already point towards the changing composition of the economic system as being a determinant of economic development. A Schumpeterian explanation of economic development would stress the important role which can be played by a country being first to introduce new technologies or organizational forms. It is difficult to justify the investment in new technologies by some countries other than by the expectation that such investment will lead to economic advantage. If variety is also a determinant of future economic development, to design the right composition of an economic system and to create favorable conditions for variety growth become important policy objectives.

The analysis of economic development in terms of variety growth does not deny the importance of efficiency growth. On the contrary, the two trends can be thought

\footnotetext{
${ }^{3}$ It must be pointed out that, in this context, variety can be used at a higher level of aggregation than the traditional one prevalent in much of the economic literature on the subject (Dixit and Stiglitz 1977; Lancaster 1975). While traditionally variety measured the degree of differentiation of a product group, in the present paper it is used to measure the degree of differentiation of economic systems at different levels of aggregation, starting from a firm or an individual product and ending with the world economy. In this paper, then, variety is a measure of the extent of differentiation of the economic system as a whole.
} 
of as being complementary. We formulate the following two general hypotheses that link efficiency and variety to economic development:

Hypothesis 1: The growth in variety is a necessary requirement for long-term economic development.

Hypothesis 2: Variety growth, leading to new sectors, and productivity growth in pre-existing sectors, are complementary and not independent aspects of economic development.

These two hypotheses can be justified by the imbalance between productivity growth and demand growth (Pasinetti 1981, 1993; Saviotti and Pyka 2004). For a closed economy, a continuous increase in productivity with demand reaching a saturation point will cause an imbalance. That such a saturation point can arise was initially pointed out by Engel, who discovered that expenditures on given types of goods and services did not rise as fast as income per head. If the economy were constituted by a constant set of activities, in presence of growing productivity, it would become possible to produce all demanded goods and services with a decreasing proportion of the resources used as inputs, including labor. This imbalance would then constitute a bottleneck for economic development, as structural unemployment would occur. The addition of new goods and services to the economic system, that is, a change in composition leading to a growth in variety, can be a form of compensation for the potential displacement of labor and of other resources. Variety growth is then required for the long term continuation of economic development. On the other hand, new goods and services can only be generated by means of search activities. The resources required for these activities can only come from the increases in efficiency of pre-existing sectors. ${ }^{4}$

The approach adopted here is explicitly Schumpeterian (Schumpeter 1934), in the sense that the increasing efficiency with which a constant, pre-existing, set of activities is performed in the course of time constitutes the circular flow, while the new activities are created by innovations that are the true determinants of long term economic development. The growing productivity of the routines constituting the circular flow creates the resources required for innovation, without which economic development would come to a halt. The consequence of the emergence of new activities is a qualitative change in the economic system, that is, a change in the number and type of distinguishable objects produced by means of all the activities of the economic system. However, the use of variety in this paper requires some reconsideration of the Schumpeterian concept of creative destruction. In principle, structural change could give rise to the emergence of a given number of new activities and to the extinction of the same number of older activities, thus making a zero contribution to net variety. Aghion and Howitt (1992, 1998, 2005) stress that it

\footnotetext{
${ }^{4}$ The claims that (1) the variety of economic system has grown, and, (2) has to grow in order to allow the further development of the system, find support in the endogenous growth literature. Amongst recent endogenous growth models, those by Romer (1990) contribute to the debate about variety by assuming that R\&D activities create new types of capital goods which then accumulate in the economy. Although Romer does not use explicitly the concept of variety, in his models at least the variety of capital goods is bound to increase during the process of economic development. This model has also motivated some empirical research testing the relationship between variety and economic growth using employment data (Funke and Ruhwedel 2001a).
}

Springer 
is precisely the substitution older innovations by new ones which constitutes the Schumpeterian character of their endogenous growth models. We depart from this interpretation of creative destruction and maintain that the long run observed growth in variety simply implies that there is more creation than destruction. Often, though not always, older economic species survive alongside new ones (Saviotti 1996; Frenken et al. 1999). However, destruction is still a relevant feature of economic development because very often, though not necessarily in the majority of cases, older activities become extinct and are completely replaced by new ones. What always occurs, irrespective of the extinction of older activities, is the falling share of older activities in order to make room for the new ones. Thus, the reduction to zero of the output share of older activities (their extinction) is but a special case of their shrinking share of output to make room for newer ones. The changing composition of the economic system induced by innovation, not the one-to-one mapping of older and newer activities with the consequent extinction of the former, is the true Schumpeterian feature of economic development.

In the foregoing discussion, however, we implicitly refer to a closed economy in which aggregate demand is dependent on the size of the national economy. The potential imbalance between efficiency growth in pre-existing sectors and a lack of variety growth leading to new sectors can arise in presence of demand saturation in pre-existing sectors. On the other hand, in an open economy, demand saturation is less of a problem in the short-run. Such an economy can continue to grow while specializing in certain sectors as long as exports in these sectors keep growing. Unlike in the closed economy model, a country can escape the constraint of demand saturation by trying to gain market shares from competing countries. Such a growth path is possible if its competitive advantage becomes so great that it more than compensates for the limited integration of new sectors (Saviotti 2003). Yet, ultimately this specialization is likely to run into diminishing returns. Even if a country could gain a complete monopoly in one or more sectors, it could not compensate for the falling share of trade of its sectors of specialization as new sectors keep emerging. This implies that export variety growth is expected to promote economic growth. ${ }^{5}$ However, the possibility of a trade-off between prolonged specialization and growing variety during extended periods of time allows the existence of multiple development paths for countries.

If we accept that growing variety is a necessary requirement for long-term economic development, in closed as well as open economies, it follows that the income share of pre-existing sectors can be expected to fall gradually in the course of time. We can also expect that, however limited the extent of specialization of any country, its export variety will be lower than the world output variety at a given time. If world output variety keeps increasing following hypotheses 1 and 2 , we can expect that, ceteris paribus, the export variety of countries will also increase. We stress again that this condition applies only to the long run, and that, in the short to medium run, deviations from it can occur (Saviotti 2003).

\footnotetext{
${ }^{5}$ An approximate demonstration of this proposition is given in Saviotti (2003). There it is shown that developing countries have different catch up strategies, based on a mixture of specialization, variety growth and entry into different niches. The success of these strategies can be expected to depend among other variables on the previous production structure of the country and on the time span over which the strategy is applied. At this point, it is important to introduce the distinction between related and unrelated variety.
} 
The expected increase in export variety accompanying economic development can take on different forms. Similarly to what was done in previous studies of diversification in firms (Montgomery 1994; Teece et al. 1994) and in regions (Attaran 1986; Frenken et al. 2007), one can distinguish between related and unrelated variety. Related variety refers to the variety that exists within each sector. Such variety is related in the sense that the products and services within a sector are likely to be more closely related than the product services of two different sectors. As a consequence, the capabilities required to increase related variety are similar to the existing ones and thus easier to acquire. Unrelated variety is the variety in terms of the main sectors in the economy. The capabilities required to produce each of the unrelated varieties are very different.

Generally, an increase in related variety is easier to achieve because the capabilities and institutions present in an existing sector can be easily transferred to related sectors. Indeed, observing from the export specialization patterns of countries, most countries have historically diversified in related sectors, giving rise to a path-dependent development trajectory similar to a branching process (Haussman and Rodrik 2005; Hidalgo et al. 2007). The costs and risks of diversifying in related sectors, for a firm and a country alike, are thus expected to be relatively low. Within a short time horizon, a country increasing its export variety in related sectors can thus be expected to be more successful than a country increasing its export variety in unrelated sectors.

In spite of the previous considerations, we cannot assume that only related variety is determinant of economic development. If the world economic system keeps creating new 'economic species,' no country can afford to diversify only in the immediate neighborhood of its existing outputs. A combination of related and unrelated diversification is a more likely development strategy. These two types of diversification have payoffs on different time scales, shorter for related and longer for unrelated diversification. Thus, an increase in unrelated variety is also expected to be important for development, although over a longer time scale. Without the creation of new sectors, a country can become locked into the export of related varieties within a particular sector. This narrow specialization would make the country vulnerable to external shocks stemming from technology shifts, world price fluctuations or changes in preferences (Krugman 1993), as well from political lobbying (Grabher 1993). Second, by broadening its capabilities, a country can become more innovative, as important innovations generally stem from the recombination of previously unrelated technologies (Weitzman 1998).

We can now derive two specific hypotheses to be tested empirically below:

Hypothesis 3: Growth in related export variety promotes economic growth in the short run.

Hypothesis 4: Growth in unrelated export variety promotes economic growth with a longer time lag than in related export variety.

\section{Research design}

We measure variety using the entropy measure applied to the distribution of sectors in a country's export portfolio, where $p_{i}$ stands for the share of sector $i$ in total 黑 Springer 
exports of a country. The entropy measure increases with an increase in the number of sectors $n$ and with the evenness of the distribution of shares. Entropy $H$ is computed by:

$$
H=\sum_{i=1}^{n} p_{i} \log _{2}\left(\frac{1}{p_{i}}\right)
$$

The main advantage of the entropy measure over alternative measures, and the reason for its use in the context of studies on variety/diversification, is that entropy can be decomposed at each sectoral digit level. The decomposable nature of entropy implies that variety at several digit levels can enter a regression analysis without necessarily causing collinearity (Jacquemin and Berry 1979).

Formally, this decomposition procedure follows from the entropy formula. Let all sectors $i$ at some level of aggregation fall exclusively under a sector $S_{g}$ at some higher level of aggregation, where $g=1, \ldots, G$. One can derive the shares $P_{g}$ at the higher level of aggregation by summing the shares $p_{i}$ at the lower level of aggregation:

$$
P_{g}=\sum_{i \in S_{g}} p_{i}
$$

The entropy $H_{0}$ at the higher level', also called between-group entropy, is given by the entropy formula:

$$
H_{0}=\sum_{g=1}^{G} P_{g} \log _{2}\left(\frac{1}{P_{g}}\right)
$$

The entropy $H^{\prime}$ at the lower level is given by the weighted average of the withingroup entropy values, and is given by:

$$
H^{\prime}=\sum_{g=1}^{G} P_{g} H_{g}
$$

with within group entropy being:

$$
H_{g}=\sum_{i \in S_{g}} \frac{p_{i}}{P_{g}} \log _{2}\left(\frac{1}{p_{i} / P_{g}}\right)
$$

This procedure can be replicated at any level of aggregation. Following previous work on related and unrelated diversification, both at the firm level (Jacquemin and Berry 1979) and at the regional level (Attaran 1986), we apply the entropy measure at different levels of sectoral aggregation. Our three-digit export data allow for a decomposition at three digit levels. We define unrelated variety (UV) for each country as the entropy of the one-digit distribution of export shares ( $i$ standing for one-digit classes). We define semi-related variety (SV) as the weighted sum of the entropy at the two-digit level within each one-digit class ( $i$ standing for two-digit classes and $g$ standing for one-digit classes). Further, we define related variety $(R V)$ as the weighted sum of the entropy at the three-digit level within each two-digit class ( $i$ standing for three-digit classes and $g$ standing for two-digit classes). It can further 
be shown that entropy at the three-digit level equals the sum of unrelated, semirelated and related variety (Theil 1972; Frenken 2007), i.e.:

$$
H=H_{0}+H^{\prime}
$$

We compute entropy measuring using OECD trade data, which are available for OECD countries at the five-digit level from 1961 to 2003. Unfortunately, since there are many missing data, especially at the four and five digit level, we limit the analysis to the three-digit level. Also, due to missing data, we exclude the 1-digit sector "9" (commodities not elsewhere classified) and two-digit sector "35" (electricity), the years 1961, 1962 and 1963 and the countries Israel and Austria. Data for USA for 2003 were also missing.

As independent variables, we use economic growth, using data on GDP per capita $(g d p)$ and labor productivity per person employed $(l p)$. Both datasets are publicly available by the GGDC at the University of Groningen (www.ggdc.net). Due to data limitations, data on Germany after 1989 are not used.

Covering 40 years for the period 1964-2003, we compute growth for each 5-year period. This yields eight observations for each country and 160 observations in total for the pooled sample. The exact number of observations drops to 156 due to aforementioned missing data of Germany after reunification and the USA in 2003.

The equation to be estimated becomes:

$$
\ln \left(\frac{y_{i, t}}{y_{i, t-T}}\right)=\ln \left(\frac{U V_{i, t}}{U V_{i, t-T}}\right)+\ln \left(\frac{S V_{i, t}}{S V_{i, t-T}}\right)+\ln \left(\frac{R V_{i, t}}{R V_{i, t-T}}\right)+\varepsilon
$$

where $T$ stands for the length of a growth period (here, $T=5$ ).

\section{Results}

In the Annex, we provide the total entropy level for the exports of 20 OECD countries for the period 1961-2004 at the three-digit level, as well as the decomposed entropy measures indicating unrelated, semi-related and related variety. Note again that the total entropy level at the three-digit level is equivalent to the sum of unrelated, semi-related and related variety.

A number of patterns emerge from the graphs:

1. First, the countries which, during the period of observation, had the highest level of economic development also had the highest overall export variety. However, such export variety changed very little during the period of observation,

2. Countries which, during the period of observation, started with a very low level of economic development relative to the leaders but had a fast process of catching up, including Finland, Greece, New Zealand and Turkey, had a very fast rise in their export variety,

3. The distribution of overall export variety within its components (unrelated, semi-related, related) does not seem to follow a generally identifiable pattern. Each country seems to follow a different path, at least judging by a visual inspection of the diagrams in the Annex, 
4. Some countries show a rather strange though interesting behavior. In particular, Norway experienced a decline in export variety, while Ireland experienced export variety growth from the 1960 s to the 1980 s, followed by variety decline from the 1980 s to the end of the period of observation. ${ }^{6}$

Interestingly, the levels of import variety for all countries are roughly the same and more or less constant over time (figures not shown). The total entropy of imports is generally around 4.5, which is generally equal to or higher than export variety, reflecting the fact that most countries import a higher variety of goods and services than that they export.

Table 1 shows the OLS estimations for 12 model specifications. Models 1 to 6 show the results with GDP per capita growth as dependent variable, and Models 7 to 12 show the results for labor productivity growth as a dependent variable. Models 4 to 6 replicate model 1 to 3 , but with the dependent variable being measured 1 year later. In the same way, models 10 to 12 replicate models 7 to 9 , but with the dependent variable being measured one year later. Furthermore, some models $(3,6$, $9,12)$ include country dummies amongst the independent variables. All the variables in the models were sufficiently uncorrelated $(<.6)$ to be included jointly.

The results in Table 1 show that our hypothesis - that an increase in related export variety promotes growth - is confirmed. In all 12 regression models, the growth in related export variety $(R V)$ is positive and significant at 1 or $5 \%$ levels. This result strengthens the idea that countries profit from diversifying in related sectors, as it is easier to transplant capabilities and institutions between related sectors. Semi-related variety growth $(S V)$ does not affect growth, while unrelated variety ( $U V$ ) even has a negative effect on growth in most model specifications.

The results on the lagged variables of variety growth show different patterns. Our hypothesis concerning lagged variables holds that past unrelated variety growth (here, in the previous 5-year period) has a positive effect on growth. Indeed, such a positive influence of past unrelated variety growth on economic growth is present in five out of the eight models that include the lagged variables. We also witness a positive effect of past semi-related variety growth, which may indicate the operation of the same mechanisms as hypothesized for past unrelated variety growth.

These results provide evidence for our hypothesis on the lagged effect of unrelated variety growth on economic growth, albeit less strong than the evidence found for the immediate effect of related variety growth on economic growth. The weaker evidence displayed by lagged variables may reflect the fact that the chosen lag of 5 years does not necessarily apply for all countries and in all periods. The greater significance of related variety in the short run is explained as predicted by the greater ease with which countries can move to new but related goods and services rather than to new and completely unrelated ones. However, our results confirm that the relative significance and weight of the different components of variety vary depending on the time horizon considered. As we move towards the long run, the simple diversification towards related variety does not suffice. In the long run,

\footnotetext{
${ }^{6}$ The trends for Norway can be explained by its specialization in oil and fisheries, and the trends for Ireland by the specialization in computers and pharmaceuticals after the 1980 s following an initial growth of export variety.
} 
Table 1 Regression results

\begin{tabular}{|c|c|c|c|c|c|c|}
\hline & $\begin{array}{l}\text { Model } 1 \\
\text { growth gdp }\end{array}$ & $\begin{array}{l}\text { Model } 2 \\
\text { growth gdp }\end{array}$ & $\begin{array}{l}\text { Model } 3 \\
\text { growth gdp }\end{array}$ & $\begin{array}{l}\text { Model } 4 \\
\text { growth gdp } \\
(t+1)\end{array}$ & $\begin{array}{l}\text { Model } 5 \\
\text { growth gdp } \\
(t+1)\end{array}$ & $\begin{array}{l}\text { Model } 6 \\
\text { growth gdp } \\
(t+1)\end{array}$ \\
\hline growth & $-0.294 * *$ & $-0.385^{* *}$ & $-0.251^{*}$ & $-0.242^{*}$ & $-0.325 * *$ & $-0.268^{*}$ \\
\hline UV & $(0.110)$ & $(0.114)$ & $(0.124)$ & $(0.101)$ & $(0.097)$ & (0.108) \\
\hline growth & -0.021 & -0.135 & -0.083 & -0.082 & -0.006 & -0.019 \\
\hline SV & $(0.094)$ & (0.109) & $(0.107)$ & $(0.086)$ & $(0.093)$ & (0.093) \\
\hline growth & $0.215^{* *}$ & $0.252 * *$ & $0.197 *$ & $0.153 *$ & $0.180 * *$ & $0.190 *$ \\
\hline RV & $(0.072)$ & $(0.076)$ & $(0.083)$ & $(0.066)$ & $(0.065)$ & $(0.072)$ \\
\hline growth & & $0.239 *$ & $0.350 * *$ & & $0.276 * *$ & $0.297 * *$ \\
\hline $\begin{array}{l}\text { UV } \\
\text { lag }\end{array}$ & & $(0.111)$ & (0.128) & & $(0.095)$ & $(0.111)$ \\
\hline growth & & $0.042(0.092)$ & $0.078(0.092)$ & & $0.023(0.078)$ & $0.040(0.080)$ \\
\hline $\begin{array}{l}\text { SV } \\
\text { lag }\end{array}$ & & & & & & \\
\hline growth & & -0.129 & $-0.183^{*}$ & & $-0.160 * *$ & $-0.154 *$ \\
\hline $\begin{array}{l}\text { RV } \\
\text { lag }\end{array}$ & & $(0.071)$ & $(0.078)$ & & $(0.060)$ & $(0.068)$ \\
\hline $\begin{array}{l}\text { Country } \\
\text { dummies } \\
\text { included }\end{array}$ & No & No & Yes & No & No & Yes \\
\hline $\mathrm{R} 2$ & 0.078 & 0.182 & 0.379 & 0.069 & 0.197 & 0.361 \\
\hline \multirow[t]{2}{*}{$\mathrm{N}$} & 156 & 136 & 136 & 156 & 136 & 136 \\
\hline & $\begin{array}{l}\text { Model } 7 \\
\text { growth lp }\end{array}$ & $\begin{array}{l}\text { Model } 8 \\
\text { growth lp }\end{array}$ & $\begin{array}{l}\text { Model } 9 \\
\text { growth lp }\end{array}$ & $\begin{array}{l}\text { Model } 10 \\
\text { growth lp } \\
(\mathrm{t}+1)\end{array}$ & $\begin{array}{l}\text { Model } 11 \\
\text { growth lp } \\
(\mathrm{t}+1)\end{array}$ & $\begin{array}{l}\text { Model } 12 \\
\text { growth lp } \\
(\mathrm{t}+1)\end{array}$ \\
\hline $\begin{array}{l}\text { growth } \\
\text { UV }\end{array}$ & $-.231 *(.104)$ & $-.366^{* *}(.096)$ & $-.247 *(.097)$ & $-.096(.096)$ & $-.230 * *(.083)$ & $-.227 *(.089)$ \\
\hline $\begin{array}{l}\text { growth } \\
\text { SV }\end{array}$ & $.017(.089)$ & $-.102(.092)$ & $-.053(.084)$ & $.082(.083)$ & $-.034(.079)$ & $-.016(.077)$ \\
\hline $\begin{array}{l}\text { growth } \\
\text { RV }\end{array}$ & $.208 * *(.068)$ & $.214 * *(.064)$ & $.165 *(.065)$ & $.131 *(.063)$ & $.152 * *(.055)$ & $.188 *(.060)$ \\
\hline $\begin{array}{l}\text { growth } \\
\text { UV } \\
\text { lag }\end{array}$ & & $.108(.093)$ & $.209 *(.100)$ & & $.032(.081)$ & $-.007(.092)$ \\
\hline $\begin{array}{l}\text { growth SV } \\
\text { lag }\end{array}$ & & $.134(.077)$ & $.172 *(.072)$ & & $.149 *(.067)$ & $.177 * *(.067)$ \\
\hline $\begin{array}{l}\text { growth } \\
\text { RV } \\
\text { lag }\end{array}$ & & $.030(.060)$ & $-.013(.061)$ & & $-.012(.052)$ & $.014(.056)$ \\
\hline $\begin{array}{l}\text { Country } \\
\text { dummies } \\
\text { included }\end{array}$ & No & No & Yes & No & No & Yes \\
\hline $\mathrm{R} 2$ & 0.078 & 0.233 & 0.491 & 0.055 & 0.150 & 0.357 \\
\hline$N$ & 156 & 136 & 136 & 156 & 136 & 136 \\
\hline
\end{tabular}

**indicates significance at.01 level, * indicates significance at.05 level (standard error between brackets)

countries need to introduce more radically different goods and services into their output and trade structure if they want to keep growing. The lower effectiveness of unrelated variety in the short run can be explained by a time path in which costs start rising long before profits start emerging. It follows that the creation of new economic species is a long run process which must be prepared for with a considerable advance with respect to the moment when payoffs will be obtained. 
The inclusion of country dummies in some of the models $(3,6,9,12)$ significantly increase the model performance compared to models $(2,5,8,11)$, as indicated by an increase in the $\mathrm{R}^{2}$ change and its significance for the two sets of independent variables. Dummies here control for country-specific growth rates and, as such, can be understood as reflecting national structures affecting growth. (We understand such as structures as mainly reflecting institutions.) The increased significance due to the introduction of country dummies can be explained by the inter-country asymmetries discussed above. The country dummy variables represent the presence of persistent asymmetries, while the effects of the three components of variety represent secular trends. In an economic system in which both country specificities and secular trends determine development paths, we can expect a better fit to the data to be provided when independent variables representing both phenomena are used.

\section{Discussion}

The results obtained in this paper constitute a partial, but important, confirmation of the role played by structural change in economic development. They show that related export variety is a determinant of GDP per capita and labor productivity growth for OECD countries during the period 1964-2003. While only related variety is a determinant of growth in the short run, unrelated variety can become a determinant if we lengthen the time horizon. The two results can be reconciled if we consider that, while in the short run a development path attempting to jump over long distances in product space is likely to fail, even a path proceeding by small steps and incremental modifications in product space is likely to run against diminishing returns in the long run if it is not complemented by the creation of completely new goods and services, that is, by unrelated variety growth. Thus, different types of diversification patterns affect growth at different time scales. Our results prove the existence of constraints and barriers affecting the paths of economic and technological development. These results, however, are based on regressions that do not control for other factors affecting growth, such as employment, savings and R\&D (since these data are not available), except for country-specific growth trends. Therefore, future efforts should be devoted at analyzing datasets that include such control variables, for example, by replicating the present study using variety, income and productivity levels rather than their changes over time (cf., Funke and Ruhwedel 2001b; Funke and Ruhwedel 2005). One may also want to develop alternative relatedness indicators that better capture the degree of relatedness between sectors in terms of the required firm capabilities (e.g., Breschi et al. 2003; Bryce and Winter 2006; Nesta and Saviotti 2005, 2006).

From an evolutionary perspective, our finding that related variety is an important determinant of growth in OECD countries has an interesting interpretation. Related variety is measured at a level of aggregation lower than unrelated variety, where we can expect any two product groups to have a greater similarity than at a higher level of aggregation. The fact that related variety is a determinant of growth means that diversification is more efficiently realized in related sectors. This reflects the idea that countries cannot easily jump over long distances in product space, which 
presumably also means in knowledge space. Countries can progress from exporting basic textiles to more refined textiles more easily than from textiles to nuclear power. This implies that, even in presence of important secular trends, such as growing efficiency or growing variety, a country is bound to start with a given productive structure which contributes to determine its development path in the short to medium run. This development path will lead each country from its initial position in product space to a final position through a series of intermediate steps as in a branching process (Frenken and Boschma 2007).

The results of our study are in line with those reported in a recent paper by Hidalgo et al. (2007), in which the authors represent the structure of countries' exports as a network in which the links are defined by the proximity in product space. They show that countries at lower levels of economic development can progress by beginning to export more sophisticated products, but they can only move to products relatively close to their initial ones in product space. Thus, the structure of product space constructed on the basis of exports maps onto a structure of levels of economic development in which few rich countries control the most advanced technologies and products, while countries at lower levels of economic development have to limit themselves to the less advanced technologies and product groups. These results do not prevent less developed countries from developing, but imply that such development is subject to barriers that not all countries manage to overcome. The nature of these barriers and the types of institutions and policies which can help countries to overcome them is an extremely important field of study.

Acknowledgment Comments by Frank Neffke are gratefully acknowledged. All errors remain ours.

\section{Appendix}

Annex

Source: OECD trade databases

AUS is Australia

CAN is Canada

CHE is Switzerland

DEU is Germany

DNK is Denmark

ESP is Spain

FIN is Finland

FRA is France

GBR is Great Brittain

GRC is Greece

IRL is Ireland

ITA is Italy

JPN is Japan

NLD is Netherlands

NOR is Norway

NZL is New Zealand

PRT is Portugal

Dinger 
SWE is Sweden

TUR is Turkey

USA is USA
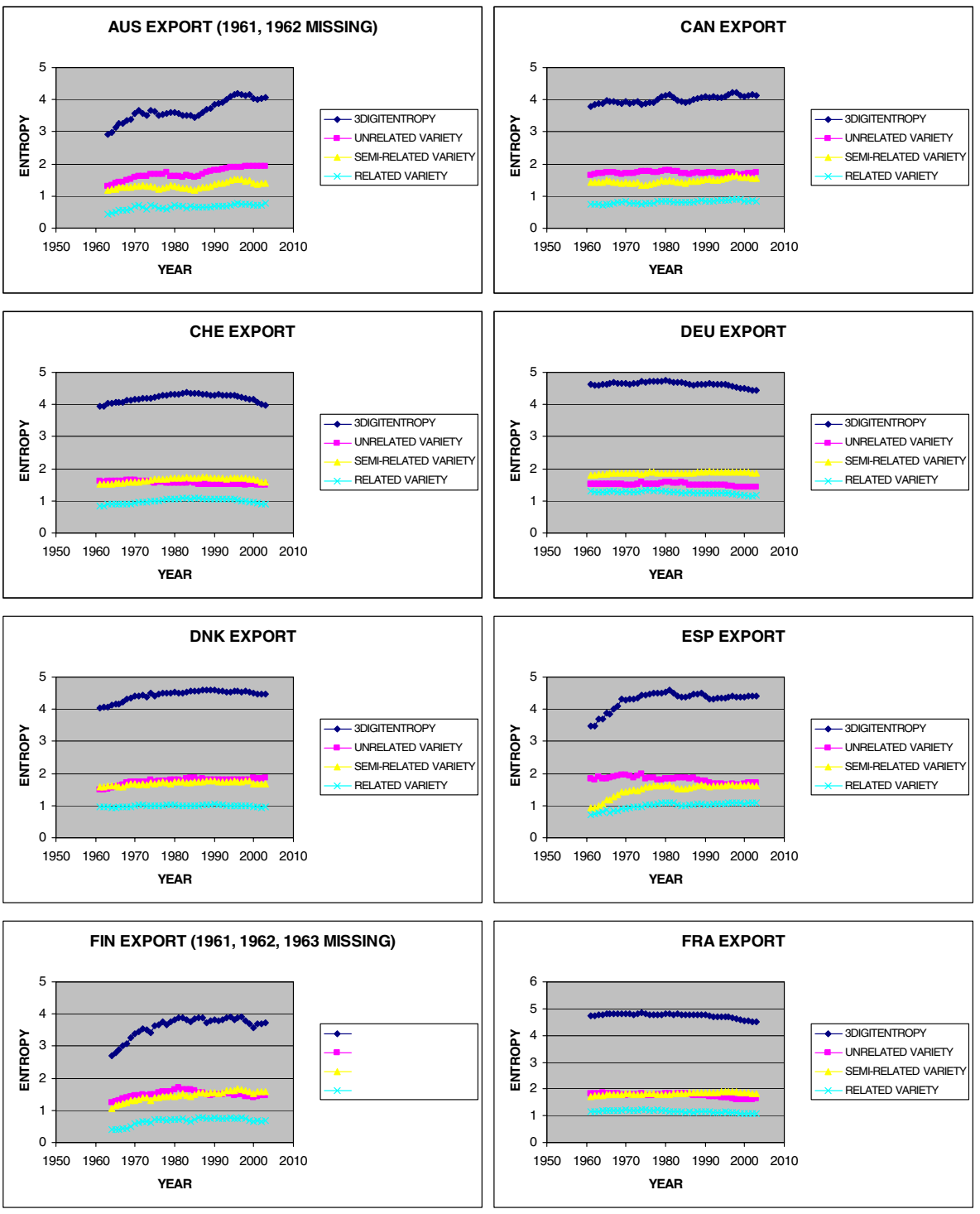

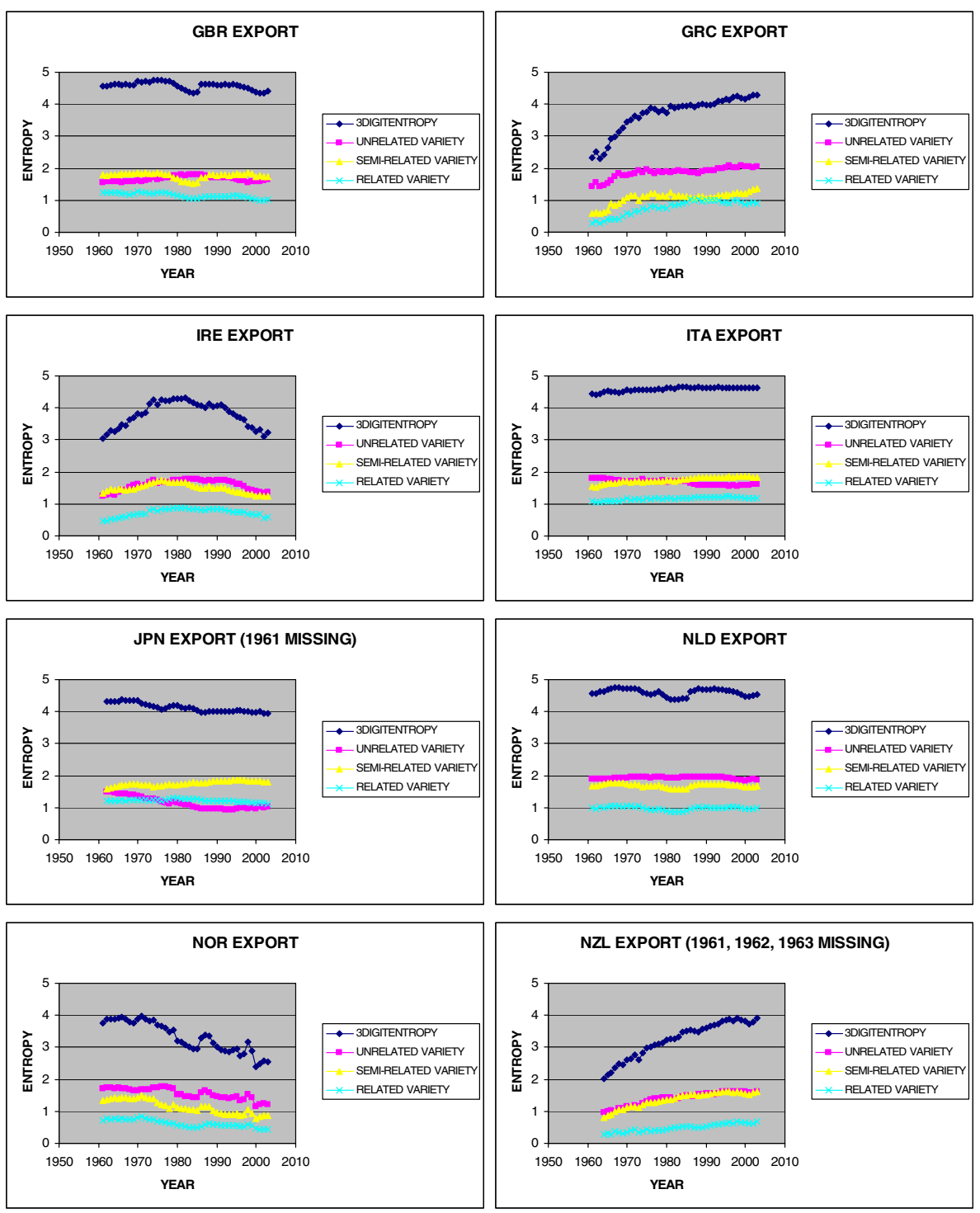

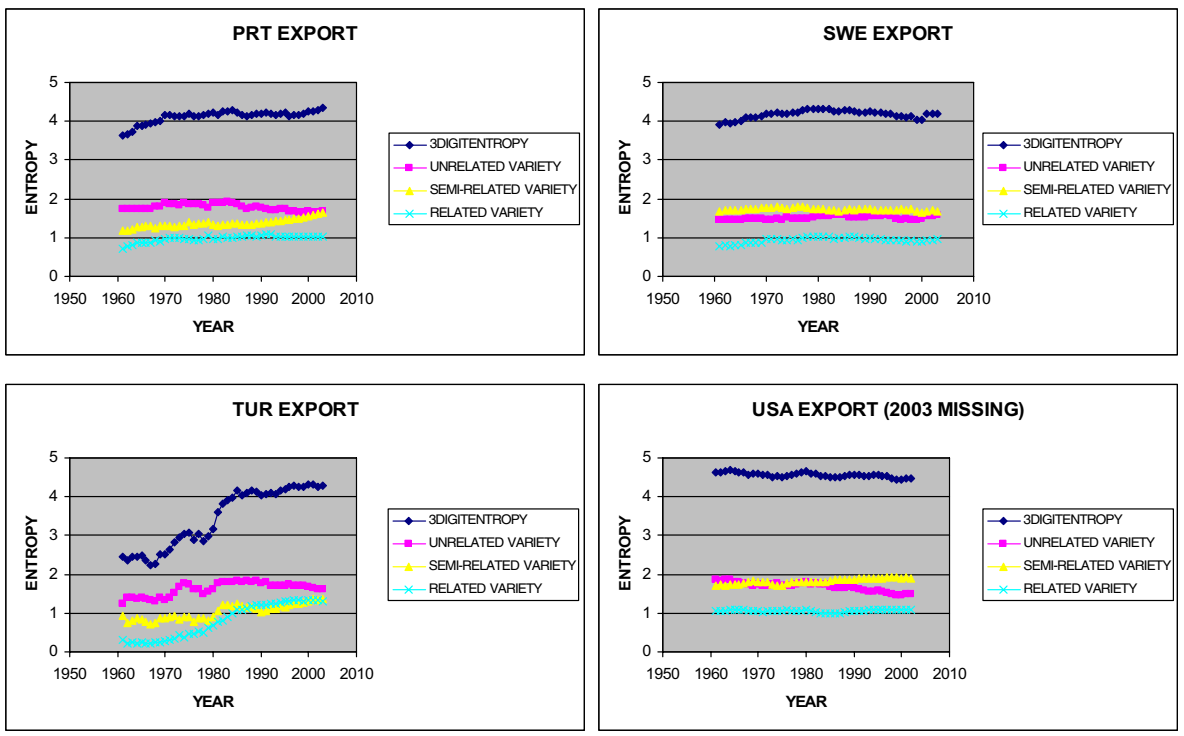

\section{References}

Aghion P, Howitt P (1992) A model of growth through creative destruction. Econometrica 60(2):323-351 Aghion P, Howitt P (1998) Endogenous growth theory. MIT Press Cambridge, MA

Aghion P, Howitt P (2005) Appropriate growth policy: a unifying framework, lecture, XXth Annual Congress of the European Economic Association, Amsterdam, August 25, http://post.economics. harvard.edu/faculty/aghion/papers.html

Attaran M (1986) Industrial diversity and economic performance in U.S. areas. Ann Reg Sci 20:44-54

Breschi S, Lissoni F, Malerba F (2003) Knowledge relatedness in firm technological diversification. Res Pol 32(1):69-87

Bryce B, Winter S (2006) A general inter-industry relatedness index, Working Paper 06-31, Center for Economic Studies, U.S. Census Bureau

Cornwall J (1977) Modern capitalism: its growth and transformation. Martin Robertson, London

Dixit AK, Stiglitz JE (1977) Monopolistic competition and optimum product diversity. Am Econ Rev 67:297-308

Edquist C (ed) (1997) Systems of innovation: technologies, institutions and organizations. Pinter, London

Fagerberg J (2000) Technological progress, structural change and productivity growth: a comparative study. Struct Chang Econ Dyn 11(4):393-411

Fagerberg J, Verspagen B (2002) Technology-gaps, innovation diffusion and transformation: an evolutionary interpretation. Res Pol 31:1291-1304

Freeman C (1987) Technology policy and economic performance: lessons from Japan. London, Pinter

Frenken K (2007) Entropy statistics and information theory. In: Hanusch H, Pyka A (eds) The Elgar companion to Neo-Schumpeterian economics. Edward Elgar, Cheltenham, UK and Northampton MA, pp $544-555$

Frenken K, Boschma RA (2007) A theoretical framework for evolutionary economic geography: industrial dynamics and urban growth as a branching process. J Econ Geogr 7(5):635-649

Frenken K, Saviotti PP, Trommetter M (1999) Variety and niche creation in aircraft, helicopters, motorcycles and microcomputers. Res Pol 28:469-488

Frenken K, van Oort FG, Verburg T (2007) Related variety, unrelated variety and regional economic growth. Reg Stud 41(5):685-697 
Funke M, Ruhwedel R (2001a) Product variety and economic growth: Empirical evidence for the OECD countries, IMF Staff papers, 48, No. 2

Funke M, Ruhwedel R (2001b) Export variety and export performance: empirical evidence from East Asia. J Asian Econ 12:493-505

Funke M, Ruhwedel R (2005) Export variety and economic growth in East European transition economies. Econ Transit 13(1):25-50

Grabher G (1993) The weakness of strong ties: the lock-in of regional development in the Ruhr area. In: Grabher G (ed) The Embedded Firm. Routledge, London, pp 255-277

Hausmann R, Hwang J, Rodrik D (2005) What you export matters, KSG Working Paper No. RWP05-063, Harvard University

Helpman E (2004) The mystery of economic growth. Harvard University Press, Cambridge Mass

Hidalgo CA, Klinger B, Barabasi A-L, Hausmann R (2007) The product space conditions the development of nations. Science 317(5837):482-487

Jacquemin AP, Berry CH (1979) Entropy measure of diversification and corporate growth. J Ind Econ 27:359-369

Krugman PR (1993) Lessons of Massachusetts for EMU. In: Torres F, Giavazzi F (eds) Adjustment and Growth in the European Monetary Union. Cambridge University Press, Cambridge, pp 241-269

Kuznets S (1965) Economic growth and structure. Norton, New York

Lancaster KJ (1975) Socially optimal product differentiation. Am Econ Rev 65:567-585

Landes D (1998) The wealth and poverty of nations. Norton, New York

Lundvall BA (ed) (1992) National systems of innovation. Pinter, London

Montgomery CA (1994) Corporate diversification. J Econ Perspect 8:163-178

Nelson RR (1995) Co-evolution of industry structure, technology and supporting institutions, and the making of comparative advantage. Int J Econ Bus 2(2):171-184

Nesta LJJ, Saviotti PP (2005) Coherence of the knowledge base and the firm's innovative performance: evidence from the US pharmaceutical industry. J Ind Econ 53:105-124

Nesta LLJ, Saviotti PP (2006) Firm knowledge and market value in biotechnology. Ind Corp Change 15:625-652

North DC (1990) Institutions, institutional change and economic performance. Cambridge University Press, Cambridge

Pasinetti LL (1981) Structural change and economic growth. Cambridge University Press, Cambridge

Pasinetti LL (1993) Structural economic dynamics. Cambridge University Press, Cambridge

Romer P (1990) Endogenous technical progress. J Polit Econ 98:71-102

Salter WEG (1960) Productivity and technical change. Cambridge University Press, Cambridge

Saviotti PP (1996) Technological evolution, variety and the economy. Edward Elgar, Aldershot

Saviotti PP (2003) On the policy implications of variety growth for developing and industrializing countries. In: Cassiolato JE, Lastres HMM, Maciel ML (eds) Systems of innovation and development, evidence from Brazil. Edward Elgar, Cheltenham

Saviotti PP, Pyka A (2004) Economic development by the creation of new sectors. J Evol Econ 14(1):1-35

Schumpeter J (1934) The Theory of Economic Development. Mass, Harvard University Press, Cambridge original edition 1912

Teece DJ, Rumelt R, Dosi G, Winter S (1994) Understanding corporate coherence: Theory and evidence. J Econ Behav Organ 23(1):1-30

Theil H (1972) Statistical decomposition analysis. North Holland, Amsterdam

Weitzman M (1998) Recombinant growth. Q J Econ 113(2):331-360 